\title{
A randomised controlled trial of multimodal physiotherapy versus advice for recent onset, painful cervical radiculopathy - the PACeR trial protocol
}

\author{
Louise Keating $^{1 *}$ (D), Caroline Treanor ${ }^{2}$, Julie Sugrue ${ }^{2}$, Dara Meldrum ${ }^{3}$, Ciaran Bolger ${ }^{4}$ and Catherine Doody ${ }^{5}$
}

\begin{abstract}
Background: A research gap exists for optimal management of cervical radiculopathy in the first 12 weeks and short term natural history of the condition is somewhat unclear, although thought to be favourable. The primary aim of this assessor blinded, superiority, 2 parallel group randomised controlled trial is to investigate the effects of a 4 week physiotherapy programme (6-8 sessions) of manual therapy, exercise and upper limb neural unloading tape, compared to a control of weekly phone advice; on disability, pain and selected biopsychosocial measures, in acute and sub-acute cervical radiculopathy patients. A secondary aim is to identify whether any baseline variables, symptom duration or group allocation can predict outcome.

Methods: Participants are recruited from GP referrals in an urban setting, from a neurosurgery non-urgent waiting list and from self-referral through Facebook advertising. Eligible participants $(n=64)$ are diagnosed with radiculopathy based on a clinical prediction rule and must have symptoms of unilateral, single level, radiculopathy for between 2 and 12 weeks, without having yet received physiotherapy. Random 1:1 group allocation (using variable block sizes), allocation concealment, blinded assessment and intention to treat analysis are being employed. Treatment is provided by clinical specialist physiotherapists in primary and secondary care settings. Outcomes are measured at baseline, 4 (primary endpoint) and 12 weeks. Participants' report of pain, disability and their rating of recovery is also recorded by telephone interview at 6 months. Statistical analysis of between group differences will be performed with ANOVAs and MANOVAs, and multivariable regression analysis will be undertaken to explore predictor variables. Ethical approval for this study has been received from the Beaumont Hospital and Irish College of General Practitioners Research Ethics Committees. The trial is registered at ClinicalTrials.gov (NCT02449200).
\end{abstract}

Discussion: An internal pilot study to test retention and recruitment strategies led to trial expansion and this is now a multi centre trial involving 5 clinical sites.

Trial registration: NCT02449200. Registered 20/05/15.

Keywords: Cervical radiculopathy, Physiotherapy, Manual therapy, Exercise, Unloading tape, Pressure algometry

\footnotetext{
* Correspondence: Ikeating@rcsi.ie

${ }^{1}$ School of Physiotherapy, Royal College of Surgeons in Ireland (RCSI), Dublin,

Ireland

Full list of author information is available at the end of the article
}

(c) The Author(s). 2019 Open Access This article is distributed under the terms of the Creative Commons Attribution 4.0 International License (http://creativecommons.org/licenses/by/4.0/), which permits unrestricted use, distribution, and reproduction in any medium, provided you give appropriate credit to the original author(s) and the source, provide a link to the Creative Commons license, and indicate if changes were made. The Creative Commons Public Domain Dedication waiver (http://creativecommons.org/publicdomain/zero/1.0/) applies to the data made available in this article, unless otherwise stated. 


\section{Background}

Cervical radiculopathy (CR) has been defined by the North American Spine Society (NASS) as pain in a radicular pattern in one or both upper extremities related to compression and/or irritation of one or more cervical nerve roots, with signs and symptoms including varying degrees of sensory, motor, and reflex changes in addition to dysaesthesia and paraesthesia [1]. People with CR often experience high levels of pain and disability [2] and present to primary carers seeking diagnosis, reassurance and treatment, for a condition thought to have a favourable natural history of recovery over weeks and months [3, 4]. Ten years have passed since the Taskforce on Neck Pain highlighted the existence of a research gap for its optimal management [5], during the World Health Organisation's (WHO) Bone and Joint Decade (2000-10); and although several clinical guidelines now exist for CR management [1, 3, 6, 7], they often rely heavily on consensus and have universally highlighted the paucity of high quality, randomised controlled trials.

The lack of quality trials is most evident in recent onset (12 weeks) CR, making evidence-based clinical decision-making a challenge for primary carers. Danish clinical guidelines recommend monitoring the individual patient's clinical course to guide treatment decisions during this timeframe [6]. With a prevalence less than half that seen for lumbar radiculopathy [8], trial recruitment for recent onset (less than 3 months) CR is challenging.

Conservative treatment approaches described to date, have included pharmacology, advice to remain active, manual therapy, exercise, acupuncture, traction, collars and epidural injection [5, 6]. Manual therapy can include muscle energy techniques, high velocity manipulation or low velocity mobilisation of the cervical and/or thoracic spine, soft-tissue mobilisation and neural mobilisation techniques $[9,10]$. Exercise in cohort studies and clinical trials has included mobility exercises, deep neck flexor and/or shoulder muscle endurance and strengthening $[11,12]$.

Not surprisingly, given the small evidence base for conservative management of $\mathrm{CR}$, little is known about predictors of good clinical outcome. Cleland et al. [11] identified a four-variable model that detected participants who were most likely to demonstrate short-term, i.e. after 1 month, improvement with conservative treatment. This model included participants who were older than 54 years, whose dominant arm was not affected, whose symptoms were not aggravated by cervical flexion and who received multi-modal physiotherapy made up of manual therapy, cervical traction and deep neck flexor strengthening for at least half of their visits to the clinic. When all four variables were present, the positive likelihood ratio was 8.3 (95\% CI $=1.9-63.9)$ [11].
The PACeR trial protocol is registered at ClinicalTrials.gov (NCT02449200) and is investigating the effectiveness of multimodal physiotherapy in comparison to an advice control, in recent onset CR.

\section{Aims}

The trial's primary aim is to investigate the effects of a multimodal physiotherapy (MP) programme on the independent primary outcome measures of disability, using the Neck Disability Index [13]; and pain, using the NPRS for both neck and arm pain at 4 weeks [14].

Secondary aims are;

To investigate the effects of the MP programme on selected biopsychosocial outcome measures at 4 and 12 weeks;

I. Patient reported outcome measures -

- Health-related quality of life using the SF-12 version 2 Health Survey [15].

- Mood using the Hospital Anxiety Depression Scale (HADS) [16].

- Fear avoidance using the Fear Avoidance Belief Questionnaire (FABQ) Neck [17, 18].

- Patient rating of recovery using the Global Rating of Change scale [19].

II. Clinical physical examination measures -

- Cervical range of motion measured with a CROM 3 device (Performance Attainment Associates, USA). Flexion, extension, bilateral side flexion and rotation are being measured. - Pressure pain threshold (PPT) measured with pressure algometry [20], and the Upper Limb Neurodynamic Test (ULNT) 1 [21, 22] as measures of nerve mechanosensitivity.

- To identify whether any of the biopsychosocial outcome measures, as well as PainDETECT [23] at baseline, symptom duration and group allocation; can predict outcome (pain and disability) at 3 months.

\section{Hypothesis}

A 4 week multimodal physiotherapy programme will lead to changes in self-reported disability and pain, compared to only advice to stay active, in patients with recent onset CR. The null hypothesis is that there will be no difference in pain and disability between the intervention group receiving a multimodal physiotherapy programme, and the control group receiving advice. Both groups can also continue to use medication throughout the trial, as prescribed by their GP. 


\section{Methods}

\section{Study design}

The PACeR trial is an exploratory, two parallel group, assessor-blinded, multi-centre randomised controlled trial, with a primary endpoint of pain and disability at 4 weeks. This is a superiority trial to investigate a novel, complex physiotherapy intervention using allocation concealment, blocked randomisation and a 1:1 allocation ratio. The SPIRIT statement and CONSORT guidelines are guiding the reporting and conduct of the study [24, 25]. Ethical approval for this study has been granted by the medical research ethics committees of Beaumont Hospital (REC ref. 14/85), the Irish College of General Practitioners (ICGP) and the Royal College of Surgeons in Ireland (RCSI). Recruitment is via GP referral, selfreferral through social media advertising, and initially, also from a waiting list of non-urgent referrals to a national neurosurgery centre. Five clinical centres (1 hospital and 4 private practices) are currently providing the trial's interventions. Physiotherapy is provided by postgraduate master's level or clinical specialist musculoskeletal physiotherapists.

\section{Eligibility criteria}

Adults with single-level cervical radiculopathy of less than 12 weeks duration are eligible to participate. Inclusion \& exclusion criteria are adapted from studies of similar cohorts [26, 27].

Inclusion criteria:

- Participants aged 18 years or older.

- Meet criteria for CR diagnosis on a clinical prediction rule (CPR) by demonstrating positive responses to at least 3 of the following clinical tests: Spurling's Test, Upper Limb Neural Tissue Provocation Test 1 (ULNT 1), Cervical Distraction Test, and cervical rotation (less than $60^{\circ}$ ) on the symptomatic side [28].

- Complains of neck or periscapular pain in addition to radicular pain, paraesthesia or numbness in the upper limb; aggravated by neck posture or movement [29].

- Symptom duration must be greater than 2 weeks and less than 3 months.

- Mean of Numerical Pain Rating Scale (NPRS) scores for both neck and arm pain must be $\geq 3 / 10$.

- Fluent in spoken \& written English.

\section{Exclusion criteria:}

- Previous physiotherapy or manual treatment to cervical spine within past 6 months.

- Previous epidural injection since the onset of current symptoms.
- Prior surgery to the cervicothoracic spine or currently symptomatic upper limb.

- Current bilateral upper-limb symptoms.

- Myotomal paresis less than 4/5 on Medical Research Council (MRC) Scale in affected upper limb.

- Signs and symptoms suggestive of Cervical Spondylotic Myelopathy (CSM): bilateral paraesthesia, hyperreflexia, positive Babinski reflex and spasticity.

- Diagnosis of any generalised neurological disorder e.g. multiple sclerosis.

- Concurrent peripheral neuropathy affecting either upper limb e.g. carpal tunnel syndrome, thoracic outlet syndrome.

- Medical red flags suggestive of serious pathology such as neoplastic conditions, upper cervical ligamentous instability, vertebral artery insufficiency and inflammatory or

- systemic disease [30].

- Diagnosis of fibromyalgia.

- Psychiatric diagnosis in past 6 months.

- Ongoing litigation relating to cervical symptoms.

A two-step screening process is used to determine eligibility. A successful phone screen is followed by physical examination. Physical exam includes a neurological exam and manual exam of the cervical spine (C2-T2) to identify the symptomatic nerve root level.

If an MRI of the patient's cervical spine has been undertaken, the report is reviewed for concordance after the initial assessment.

\section{Interventions}

All participants are advised on CR's natural history, positions of ease, to stay active and to take prescribed medication as appropriate.

Participants allocated to the MP group receive 4 weeks (6-8 sessions) of non-provocative manual therapy, exercise and upper limb neural unloading tape (Fig. 1), as decided by the treating physiotherapist from a best-practice physiotherapy treatment manual. Previous RCTs investigating physiotherapy for nerverelated arm pain or cervical radiculopathy have involved 2 to 6 week programmes [27, 31, 32]. All participants receive lateral glide mobilisation [33] to the appropriate segmental level, applied using a treatment algorithm modified from Nee et al. [26]. Treating therapists are also permitted to use passive accessory or intervertebral mobilisations at this level, if the lateral glide does not yield clinical benefit. Additional joint mobilisations [34] to segmental levels above or below ( $\mathrm{C} 2$ to $\mathrm{T} 4)$ can also be applied, as deemed necessary by the treating physiotherapist e.g. to address segmental hypomobility. 

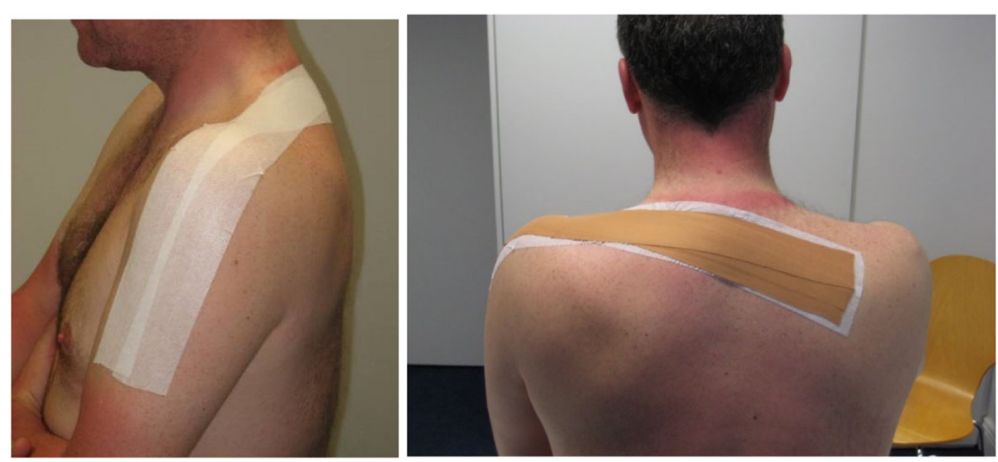

Fig. 1 Neural unloading tape. Hypoallergenic Fixomull applied first as underwrap (left) with zinc oxide applied with tension, with arm supported below the elbow (right)

All participants also receive exercise, including deep neck flexor (DNF) strengthening, mobility exercises and scapular muscle endurance exercise. The primary rationale for including exercise in this complex intervention is to achieve pain relief. Peripheral neuropathic pain and nociceptive pain mechanisms are known to co-exist in radiculopathy [35] and as such, it is to be expected that various exercises may be of benefit. Low level evidence already exists to support a variety of exercise types such as neck ROM, DNF training and scapular training, but primarily in the production of only short-term pain relief and to a lesser extent, functional improvement [31, 36], after 4 to 6 weeks of exercise. Given the painful and disabling nature of this condition, pain reduction even in the shortterm is likely to be of value to the individual patient with CR. However, medium to long term improvement in pain and function, leading to improved social participation, should be a secondary focus of any exercise intervention in this cohort. A clear understanding of axioscapular muscle dysfunction has not yet been achieved for CR and so a pragmatic approach to exercise prescription has been adopted in this trial, with the intention of providing a bespoke programme to address actual deficits identified. Non-provocative, progressive endurance and strengthening for muscles of the neck and scapular region are also embedded into the programme and prescribed at the therapist's discretion. As this intervention is of only 4 weeks' duration, participants are advised to continue appropriate exercises until their 12 week assessment.

The third element to this complex intervention is upper limb neural unloading tape, adapted from McConnell [37]. Tape is applied in order to offset the upper limb load and provide relief of arm pain. Hypoallergenic $5 \mathrm{~cm}$ wide Fixomull and $3.8 \mathrm{~cm}$ zinc oxide tape is applied for $24-48 \mathrm{~h}$. Treating therapists received 2-h training and agreed to follow the assessment and training manual. Recording of treatment sessions was done using standardised report forms.
Control group participants are phoned by a physiotherapist on a weekly basis for 4 weeks. They provide an update on their symptom profile and receive advice.

All participants are asked to forego any other physiotherapy external to the trial prior to the 12 week time point. To optimise retention, control group participants are offered treatment at 12 weeks.

\section{Outcome measures}

Table 1 outlines the SPIRIT schedule, which summarises the schedule of enrolment, interventions, and assessments.

A CPR with established diagnostic accuracy is used to confirm the presence of CR [28]. This involves 4 physical tests, which include measurement of cervical rotation and Upper Limb Neurodynamic Test (ULNT) 1. Cervical rotation range is measured with a CROM 3 device (Performance Attainment Associates, USA) made up of 3 cervical inclinometers. Reliability (ICC $=0.89-0.90$ ) and construct validity of the CROM have been demonstrated [38]. ULNT 1 is a validated pain provocation test for nerve tissue [21,22], which has also demonstrated moderate reliability $(\mathrm{kappa}=0.45)$ [39].

Participants undergo the following outcome measures at baseline, 4 and 12 weeks:

The Neck Disability Index is a ten-item self-reported questionnaire that assesses pain and associated disability [13]. The NDI is valid and reliable for use in cervical radiculopathy [40]. The Taskforce on Neck Pain considered it to be the most responsive self-assessment questionnaire available [41] due to its ability to discriminate between clinical improvement and deterioration in neck pain [42].

The Numerical Pain Rating Scale, a reliable and responsive [43] generic measure of pain [14] is being used to measure both neck and arm pain.

Cervical range of motion measured with a CROM 3 device (Performance Attainment Associates, USA). Flexion, 
Table 1 PACeR trial schedule of enrolment, interventions, and assessments adapted from original table@ SPIRIT Group [48]

\begin{tabular}{|c|c|c|c|c|c|c|c|c|c|c|}
\hline \multirow[b]{2}{*}{ TIMEPOINT } & \multicolumn{2}{|c|}{ Enrolment } & \multirow{2}{*}{$\begin{array}{c}\text { Allocation } \\
0 \\
0\end{array}$} & \multicolumn{7}{|c|}{ Post-allocation } \\
\hline & $-t_{2}$ & $-t_{1}$ & & $\begin{array}{c}\boldsymbol{t}_{1} \\
\text { week } 1\end{array}$ & $\begin{array}{c}t_{2} \\
\text { week 2 }\end{array}$ & $\begin{array}{c}t_{3} \\
\text { week } 3\end{array}$ & $\begin{array}{c}t_{4} \\
\text { week } 4\end{array}$ & $\begin{array}{c}\boldsymbol{f}_{1} \\
4 \text { weeks }\end{array}$ & $\begin{array}{c}f_{2} \\
12 \text { weeks }\end{array}$ & $\begin{array}{c}f_{3 \text { (Phone) }} \\
24 \text { weeks }\end{array}$ \\
\hline \multicolumn{11}{|l|}{ ENROLMENT: } \\
\hline $\begin{array}{l}\text { Eligibility phone } \\
\text { screen }\end{array}$ & $\mathrm{x}$ & & & & & & & & & \\
\hline \multirow[t]{2}{*}{$\begin{array}{r}\text { Eligibility physical } \\
\text { screen }\end{array}$} & & $\mathrm{x}$ & & & & & & & & \\
\hline & & $\mathrm{x}$ & & & & & & & & \\
\hline Allocation & & & $\mathrm{x}$ & & & & & & & \\
\hline \multicolumn{11}{|l|}{ INTERVENTIONS: } \\
\hline \multicolumn{11}{|l|}{$\begin{array}{r}\text { Multimodal } \\
\text { physiotherapy }\end{array}$} \\
\hline $\begin{array}{r}\text { Control advice } \\
\text { phone calls }\end{array}$ & & & & $\mathrm{x}$ & $\mathrm{x}$ & $\mathrm{x}$ & $\mathrm{x}$ & & & \\
\hline \\
\hline $\begin{array}{r}\text { Primary - NPRS } \\
\text { (Neck \& Arm) and } \\
\text { NDI } \\
\end{array}$ & & $\mathrm{x}$ & & & & & & $\mathrm{x}$ & $x$ & $x$ \\
\hline \multirow{2}{*}{$\begin{array}{r}\text { HADS, FABQ, } \\
\text { SF12v2 } \\
\text { questionnaires } \\
\text { ROM, neuro exam, } \\
\text { ULNT, PPT measures }\end{array}$} & & $\mathrm{x}$ & & & & & & $\mathrm{x}$ & $\mathrm{x}$ & \\
\hline & & $\mathrm{x}$ & & & & & & $x$ & $x$ & \\
\hline $\begin{array}{r}\text { painDETECT } \\
\text { questionnaire }\end{array}$ & & $\mathrm{x}$ & & & & & & & & \\
\hline \multirow{2}{*}{$\begin{array}{r}\text { Participant Beliefs } \\
\text { Global Rating of } \\
\text { Change Scale }\end{array}$} & & $x$ & & & & & & & & \\
\hline & & & & & & & & $x$ & $x$ & $\mathrm{x}$ \\
\hline
\end{tabular}

extension, side flexion and rotation, along with symptom response, is being measured.

The SF-12 Health Survey questionnaire will be used as a measure of quality of life (QoL) and is a practical, reliable, and valid measure of physical and mental health [44, 45].

The Hospital Anxiety and Depression Scale (HADS) and the Fear Avoidance Belief Questionnaire (FABQ) are used as psychosocial measures. The HADS [16] was developed as a tool to identify anxiety and depression in patients attending non-psychiatric hospital outpatient clinics and has been validated [46]. The FABQ was initially established to measure how patients' beliefs about physical activity and work affected their low back pain [17]. FABQ has also been shown to predict prolonged disability in neck pain patients, making it appropriate to use with this cohort of neck pain patients [18].

Pressure Pain Threshold (PPT) is measured using pressure algometry and provides a measure of mechanosensitivity of the nervous system [20]. Good inter and intrarater reliability of PPT has been established in a neck pain cohort [20]. A similar profile of altered mechanosensitivity previously found in Whiplash Associated Disorder (WAD) patients, has also been identified in patients with chronic cervical radiculopathy [47]. PPT is measured using the SENSEBox algometer (Somedic, Sweden) with a $1 \mathrm{~cm}^{2}$ head, applied at a rate of $30 \mathrm{kPa}$ / sec, at standardised sites (dermatomal key points and maximal pain area) bilaterally, and on the right anterior tibia. The mean of 3 measurements at each site, recorded at $10 \mathrm{~s}$ intervals, and a random site order is applied.

Intra-rater reliability of the PI will be verified for the ULNT 1 and PPT measurements by conducting repeat tests for 10 participants. Intraclass Correlation Coefficients (ICC) will be calculated using a one-way random effect model (for consistency agreement).

PainDETECT, a self-report questionnaire to detect neuropathic pain components, originally designed for use in low back pain [23] is also being used at baseline. This questionnaire has excellent test-retest reliability (ICC $=0.93$ ), good internal consistency (Cronbach's alpha $>0.83$ ) and high sensitivity, specificity and positive predictive value (> 80\%) [23].

Participants' overall rating of recovery is assessed using the Global Rating of Change scale (GROC) [19] at 4 and 12 week follow-up.

A final phone follow-up at 6 months will capture GROC, NPRS, NDI and any additional treatment received.

In addition to these outcome measures, baseline demographics including co-morbidities, educational level, smoking status, occupation and work status will also be captured; with change in work status noted at subsequent time points. 
Medication use for both groups is recorded weekly over the first month by physiotherapists and by the PI at follow up assessments. Adherence to home exercise prescription is also recorded on a weekly basis in the MP group and again at the 12 week assessment. The number of treatment sessions attended by participants will also serve as an additional measure of treatment adherence.

\section{Randomisation}

The allocation sequence has been generated by an independent academic colleague using a computer-generated list of random numbers and randomly varied block sizes of 4 and 6 from www.randomization.com. The allocation sequence is concealed from the PI, who enrols and consents participants. The PI informs the randomiser when a new participant has been enrolled and once randomised, the randomiser directly informs the relevant physiotherapist, who informs the participant of their group allocation by phone. Participants are randomly assigned using a 1:1 group allocation ratio. The PI is blinded to group allocation until the 12 week assessment. Given the nature of the interventions, it is not possible to blind the participants or therapists involved in providing either intervention.

\section{Sample size estimation}

The NDI and the NPRS are the independent primary outcome measures and sample size estimates were carried out for both outcome measures. An MCID for the NDI of 7 has been determined for cervical radiculopathy [48]. Using a reported NDI SD of 9.2 [48] for this patient group, with a two-sided 5\% significance level and a power of $80 \%$, a sample size of 29 participants per group is necessary. An MCID for the NPRS of 2 has been determined for mechanical neck pain, including cervical radiculopathy [43] and a SD of 1.85 [48]. Using these figures, with a two-sided 5\% significance level and a power of $80 \%$, a sample size of 15 per group was calculated. An online sample size calculator [49] for comparing means of 2 independent groups, that utilises reference tables [50] was used. The larger sample size per group calculated using the NDI was chosen and an additional 10\% was added to account for anticipated dropout. In total, a sample size of 64 participants will be recruited.

\section{Data analysis plan}

Baseline demographic characteristics and all outcome measures will be described and analysed using SPSS (IBM, version 24) or Stata statistical software (Statacorp LLC, Release 15). Descriptive characteristics will be presented for both groups following the CONSORT Statement. Data will be checked for normality using the Shapiro-Wilk test. Marginal effects will be used to calculate effect sizes for specified values for baseline differences. Results will be reported as mean differences between the groups and their 95\% confidence intervals. Poisson regression will be used where data are nonparametric (Bland and Altman, 2011).

Statistical analysis will include two-way (treatment $\mathrm{x}$ time) ANOVAs and MANOVAs for between and within-group differences and interactions. Intention to treat analysis will be the primary approach employed. A per protocol analysis will also be undertaken and results compared to assess the impact of data that is not missing at random (NMAR) (Armijo-Olivo et al., 2009).

Secondary analysis will explore if any of the baseline outcome measures, symptom duration and group allocation are predictors of outcome (pain and disability) at 3 months. Appropriate multivariable regression analysis will be performed (linear or logistic).

\section{Discussion}

An internal pilot feasibility study of $10 \%$ sample has explored the initial recruitment strategy and retention rates of the study, in alignment with MRC Guidelines (MRC, 2008). Retention strategies proved acceptable but recruitment strategies were insufficient, leading to geographical trial expansion and the addition of self-referral through social media advertising. This trial of nonprovocative multimodal physiotherapy for recent onset CR, will elucidate whether physiotherapy actively improves the pain and disability associated with the condition, when compared with advice only.

\section{Abbreviations \\ CPR: Clinical prediction rule; CR: Cervical Radiculopathy; CROM: Cervical range of motion; CSM: Cervical Spondylotic Myelopathy; FABQ: Fear Avoidance Belief Questionnaire; GROC: Global Rating of Change Scale; HADS: Hospital Anxiety and Depression Scale; ICC: Intraclass correlation coefficient; MCID: Minimal clinically important difference; MP: Multimodal physiotherapy; MRC: Medical Research Council; NASS: North American Spine Society; NDI: Neck Disability Index; NMAR: Not missing at random; NPRS: Numerical Pain Rating Scale; PI: Principal investigator; PPT: Pressure Pain Threshold; RCSI: Royal College of Surgeons in Ireland; RCT: Randomised controlled trial; ULNT: Upper Limb Neurodynamic Test; WHO: World Health Organisation}

\section{Acknowledgements \\ Eurospine, the Spine Society of Europe, provided the majority of funding for this trial. The Irish Society of Chartered Physiotherapists provided secondary funding. Statisticians in the Data Science Centre, RCSI, have provided statistical advice. Departmental colleagues in RCSI, Dr. Helen French, Fiona Daly, Deirdre English and Dr. Aine Ryan; have all assisted in managing the trial's randomisation schedule or 6 month phone follow-ups.}

\section{Authors' contributions}

LK conceived of the study, project managed the trial, screened and recruited participants, acted as blinded assessor and drafted the manuscript. CT and JS contributed to study design, including intervention design, and acted as treating physiotherapists. CB and CD participated in study design, and trial oversight and edited this manuscript. DM oversaw the significant adverse event clinical pathway and provided methodological expertise on the running of this $\mathrm{RCT}$, as well as trial oversight and editing of this manuscript. All authors read and approved the final manuscript. 


\section{Authors' information}

LK is a lecturer in physiotherapy at RCSI, Dublin and a specialist member of the Irish Society of Chartered Physiotherapists, in the area of musculoskeletal physiotherapy.

\section{Funding}

Eurospine, the Spine Society of Europe, provided funding for this study and provided initial feedback on the protocol during the funding application. No subsequent involvement in the trial has taken place.

The Irish Society of Chartered Physiotherapists have also provided funding only.

\section{Availability of data and materials}

Not applicable.

\section{Ethics approval and consent to participate}

This study has received ethical approval from the following research ethics committees -

- Beaumont Hospital (Medical Research) (REC ref. 14/85),

- Irish College of General Practitioners (ICGP),

- Royal College of Surgeons in Ireland (RCSI) (REC ref. 1106b).

Written informed consent was attained from all trial participants.

\section{Consent for publication}

Not applicable.

\section{Competing interests}

The authors declare that they have no competing interest.

\section{Author details}

${ }^{1}$ School of Physiotherapy, Royal College of Surgeons in Ireland (RCSI), Dublin, Ireland. ${ }^{2}$ Department of Physiotherapy, Beaumont Hospital, Dublin, Ireland. ${ }^{3}$ School of Medicine, Trinity College, Dublin, Ireland. ${ }^{4}$ Department of Neurosurgery, Beaumont Hospital, Dublin, Ireland. ${ }^{5}$ School of Public Health, Physiotherapy \& Population Science, University College, Dublin, Ireland.

\section{Received: 6 February 2019 Accepted: 16 May 2019}

\section{Published online: 01 June 2019}

\section{References}

1. Bono CM, Ghiselli G, Gilbert TJ, Kreiner DS, Reitman C, Summers JT, Baisden $J$, Easa J, Fernand R, Lamer T, et al. An evidence-based clinical guideline for the diagnosis and treatment of cervical radiculopathy from degenerative disorders. Spine J. 2011;11(1):64-72.

2. Haldeman S, Carroll L, Cassidy J, Schubert J, Nygren A. The bone and joint decade 2000-2010 task force on neck pain and its associated disorders executive summary. Spine. 2008;33:S5-7.

3. Blanpied PR, Gross AR, Elliott JM, Devaney LL, Clewley D, Walton DM, Sparks C, Robertson EK. Neck pain: revision 2017. J Orthop Sports Phys Ther. 2017; 47(7):A1-A83

4. Alentado VJ, Lubelski D, Steinmetz MP, Benzel EC, Mroz TE. Optimal duration of conservative management prior to surgery for cervical and lumbar radiculopathy: a literature review. Glob Spine J. 2014;4(4):279-86.

5. Hurwitz EL, Carragee EJ, Velde G, Carroll LJ, Nordin M, Guzman J, Peloso PM, Holm LW, Côté P, Hogg-Johnson S, et al. Treatment of neck pain: noninvasive interventions. Eur Spine J. 2008;17(S1):123-52.

6. Kjaer $P$, Kongsted A, Hartvigsen J, Isenberg-Jorgensen A, SchiottzChristensen B, Soborg B, Krog C, Moller CM, Halling CMB, Lauridsen HH, et al. National clinical guidelines for non-surgical treatment of patients with recent onset neck pain or cervical radiculopathy. Eur Spine J. 2017;26(9): 2242-57.

7. Cote P, Wong J, Sutton D, Shearer H, Mior S, Randhawa K, Ameis A, Carroll $L$, Nordin M, Yu H, et al. Management of neck pain and associated disorders: a clinical practice guideline from the Ontario protocol for traffic injury management (OPTIMa) collaboration. Eur Spine J. 2016;25:2002-22.

8. Salemi GSG, Meneghini F, et al. Prevalence of cervical spondylotic radiculopathy: a door-to-door survey in a Sicilian municipality. Acta Neurol Scan. 1996;93(2-3):184-8.
9. Boyles R, Toy P, Mellon J Jr, Hayes M, Hammer B. Effectiveness of manual physical therapy in the treatment of cervical radiculopathy: a systematic review. J Man Manip Ther. 2011;19(3):135-42.

10. Gross A, Langevin P, Burnie SJ, Bedard-Brochu MS, Empey B, Dugas E, FaberDobrescu M, Andres C, Graham N, Goldsmith CH, et al. Manipulation and mobilisation for neck pain contrasted against an inactive control or another active treatment. Cochrane Database Syst Rev. (2015, 9):CD004249.

11. Cleland JA, Fritz JM, Whitman JM, Heath R. Predictors of short-term outcome in people with a clinical diagnosis of cervical radiculopathy. Phys Ther. 2007;87(12):1619-32.

12. Gross AR, Paquin JP, Dupont G, Blanchette S, Lalonde P, Cristie T, Graham N, Kay TM, Burnie SJ, Gelley G, et al. Exercises for mechanical neck disorders: a Cochrane review update. Man Ther. 2016;24:25-45.

13. Vernon $\mathrm{H}$, Mior $\mathrm{S}$. The neck disability index: a study of reliability and validity. J Manip Physiol Ther. 1991;14:409-15.

14. Jensen M, Turner J, Romano J. What is the maximum number of levels needed in pain intensity measurement? Pain. 1994:58:387-92.

15. Cheak-Zamora NC, Wyrwich KW, McBride TD. Reliability and validity of the SF-12v2 in the medical expenditure panel survey. Qual Life Res. 2009;18(6): 727-35.

16. Zigmond AS, Snaith RP. The hospital anxiety and depression scale. Acta Psychiatr Scand. 1983;67:361-70.

17. Waddell G, Newton M, Henderson I, Somerville D, Main C. A fear-avoidance beliefs questionnaire (FABQ) and the role of fear-avoidance beliefs in chronic low back pain and disability. Pain. 1993;52:157-68.

18. Landers MR, Creger RV, Baker CV, Stutelberg KS. The use of fear-avoidance beliefs and nonorganic signs in predicting prolonged disability in patients with neck pain. Man Ther. 2008;13(3):239-48.

19. Jaeschke R, Singer J, Guyatt GH. Measurement of health status. Ascertaining the minimal clinically important difference. Control Clin Trials. 1989;10(4):407-15.

20. Walton DM, Macdermid JC, Nielson W, Teasell RW, Chiasson M, Brown L. Reliability, standard error and minimum detectable change of clinical pressure pain threshold testing in people with and without acute neck pain. J Orthop Sports Phys Ther. 2011:41:644-50.

21. Grieve's Modern Manual Therapy: The Vertebral Column. Edited by Boyling JD, Palastanga N, Grieve G. London: Churchill Livingstone; 1994: p. 577-585.

22. Wainner RS, Gill H. Diagnosis and nonoperative management of cervical radiculopathy. J Orthop Sports Phys Ther. 2000;30(12):728-44.

23. Freynhagen $\mathrm{R}$, Baron $\mathrm{R}$, Gockel $U$, Tolle TR. painDETECT: a new screening questionnaire to identify neuropathic components in patients with back pain. Curr Med Res Opin. 2006;22(10):1911-20.

24. Boutron I, Moher D, Altman DG, Schulz K, PftCG R. Extending the CONSORT statement to randomized trials of nonpharmacologic treatment: explanation and elaboration. Ann Intern Med. 2008;148:295-309.

25. Chan AW, Tetzlaff JM, Gotzsche PC, Altman DG, Mann H, Berlin JA, Dickersin K, Hrobjartsson A, Schulz KF, Parulekar WR, et al. SPIRIT 2013 explanation and elaboration: guidance for protocols of clinical trials. BMJ. 2013;346:e7586.

26. Nee RJ, Vicenzino B, Jull GA, Cleland JA, Coppieters MW. A novel protocol to develop a prediction model that identifies patients with nerve-related neck and arm pain who benefit from the early introduction of neural tissue management. Contemp Clin Trials. 2011;32(5):760-70.

27. Langevin P, Roy JS, Desmeules F. Cervical radiculopathy: study protocol of a randomised clinical trial evaluating the effect of mobilisations and exercises targeting the opening of intervertebral foramen [NCT01500044]. BMC Musculoskelet Disord. 2012;13:10.

28. Wainner RS, Fritz JM, Irrgang JJ, Boninger ML, Delitto A, Allison S. Reliability and diagnostic accuracy of the clinical examination and patient self-report measures for cervical radiculopathy. Spine. 2003;28(1):52-62.

29. Thoomes EJ, Scholten-Peeters GG, de Boer AJ, Olsthoorn RA, Verkerk K, Lin C, Verhagen AP. Lack of uniform diagnostic criteria for cervical radiculopathy in conservative intervention studies: a systematic review. Eur Spine J. 2012;21(8):1459-70.

30. Childs JD, Fritz JM, Piva SR, Whitman JM. Proposal of a classification system for patients with neck pain. J Orthop Sports Phys Ther. 2004;34(11):686-96; discussion 697-700.

31. Kuijper B, Tans JT, Beelen A, Nollet F, de Visser M. Cervical collar or physiotherapy versus wait and see policy for recent onset cervical radiculopathy: randomised trial. BMJ. 2009;339:b3883.

32. Nee RJ, Vicenzino B, Jull GA, Cleland JA, Coppieters MW. Neural tissue management provides immediate clinically relevant benefits without 
harmful effects for patients with nerve-related neck and arm pain: a randomised trial. J Phys. 2012;58(1):23-31.

33. Vicenzino B, Neal R, Collins D, Wright A. The displacement, velocity and frequency profile of the frontal plane motion produced by the cervical lateral glide treatment technique. Clin Biomech. 1999;14:515-21.

34. Maitland G. Vertebral manipulation. Management of Neuromusculoskeletal Disorders - volume 1. 8th edn. London: Churchill Livingstone; 2014.

35. Tampin B, Slater H, Hall T, Lee G, Briffa NK. Quantitative sensory testing somatosensory profiles in patients with cervical radiculopathy are distinct from those in patients with nonspecific neck-arm pain. Pain. 2012;153(12): 2403-14.

36. Langevin P, Desmeules F, Lamothe M, Robitaille S, Roy JS. Comparison of 2 manual therapy and exercise protocols for cervical radiculopathy: a randomized clinical trial evaluating short-term effects. J Orthop Sports Phys Ther. 2015:45(1):4-17.

37. McConnell J. The use of taping for pain relief in the management of spinal pain. In: Boyling J, Jull G, Twomey L, editors. Grieve's Modern Manual Therapy. 3rd edn. London: Elsevier Churchill Livingstone; 2004. p. 433-42.

38. Audette I, Dumas JP, Cote JN, De Serres SJ. Validity and between-day reliability of the cervical range of motion (CROM) device. J Orthop Sports Phys Ther. 2010;40(5):318-23.

39. Schmid AB, Brunner F, Luomajoki H, Held U, Bachmann LM, Kunzer S, Coppieters MW. Reliability of clinical tests to evaluate nerve function and mechanosensitivity of the upper limb peripheral nervous system. BMC Musculoskelet Disord. 2009;10:11.

40. Vernon H. The neck disability index: state-of-the-art, 1991-2008. J Manip Physiol Ther. 2008;31(7):491-502.

41. Nordin M, Carragee EJ, Hogg-Johnson S, Weiner SS, Hurwitz EL, Peloso PM Guzman J, Velde G, Carroll LJ, Holm LW, et al. Assessment of neck pain and its associated disorders. Eur Spine J. 2008;17(S1):101-22.

42. Hurst $\mathrm{H}$, Bolton J. Assessing the clinical significance of change scores recorded on subjective outcome measures. J Manip Physiol Ther. 2004;27:26-35.

43. Cleland JA, Childs JD, Whitman JM. Psychometric properties of the neck disability index and numeric pain rating scale in patients with mechanical neck pain. Arch Phys Med Rehabil. 2008;89(1):69-74.

44. Ware J, Kosinski M, Keller S. A 12-item short-form health survey: construction of scales and preliminary tests of reliability and validity. Med Care. 1996; 34(3):220-33.

45. Jenkinson C, Layte R, Jenkinson D, Lawrence K, Petersen S, Paice C, Stradling J. A shorter form health survey: can the SF-12 replicate results from the SF36 in longitudinal studies. J Public Health Med. 1997;19(2):179-86.

46. Bjellanda I, Dahlb A, Haugc T, Neckelmannd D. The validity of the hospital anxiety and depression scale: an updated literature review. J Psychosom Res. 2002;52:69-77.

47. Chien A, Eliav E, Sterling M. Whiplash (grade II) and cervical radiculopathy share a similar sensory presentation: an investigation using quantitative sensory testing. Clin J Pain. 2008;24(7):595-603.

48. Cleland JA, Fritz JM, Whitman JM, Palmer JA. The reliability and construct validity of the neck disability index and patient specific functional scale in patients with cervical radiculopathy. Spine. 2006;31(5):598-602.

49. Chang, A. 1999. Sample size calculator for comparing means of two independent groups [Online]. Dept of Obstetrics Gynaecology, The Chinese University of Hong Kong. Available: http://department.obg.cuhk.edu.hk/ researchsupport/Sample_size_CompMeanIndependent.asp. Accessed 15 Jan 2014.

50. Machin D, Campbell M, Fayers P, Pinol A. Sample Size Tables for Clinical Studies, Second Ed. Oxford: Blackwell Science; 1997.

\section{Publisher's Note}

Springer Nature remains neutral with regard to jurisdictional claims in published maps and institutional affiliations.

Ready to submit your research? Choose BMC and benefit from:

- fast, convenient online submission

- thorough peer review by experienced researchers in your field

- rapid publication on acceptance

- support for research data, including large and complex data types

- gold Open Access which fosters wider collaboration and increased citations

- maximum visibility for your research: over $100 \mathrm{M}$ website views per year

At BMC, research is always in progress.

Learn more biomedcentral.com/submissions 